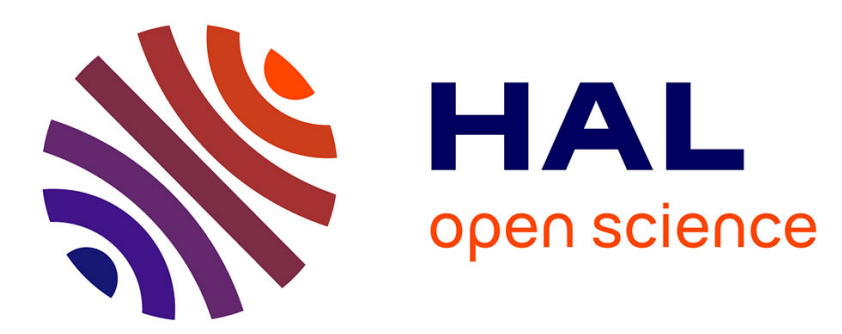

\title{
Acoustic and diving behavior of sperm whales (Physeter macrocephalus) during natural and depredation foraging in the Gulf of Alaska
}

Delphine Mathias, Aaron Thode, Jan Straley, John Calambokidis, Gregory S. Schorr, Kendall Folkert

\section{To cite this version:}

Delphine Mathias, Aaron Thode, Jan Straley, John Calambokidis, Gregory S. Schorr, et al.. Acoustic and diving behavior of sperm whales (Physeter macrocephalus) during natural and depredation foraging in the Gulf of Alaska. Journal of the Acoustical Society of America, 2012, pp.518-532. 10.1121/1.4726005 . hal-00904056

\section{HAL Id: hal-00904056 https://hal.science/hal-00904056}

Submitted on 13 Nov 2013

HAL is a multi-disciplinary open access archive for the deposit and dissemination of scientific research documents, whether they are published or not. The documents may come from teaching and research institutions in France or abroad, or from public or private research centers.
L'archive ouverte pluridisciplinaire HAL, est destinée au dépôt et à la diffusion de documents scientifiques de niveau recherche, publiés ou non, émanant des établissements d'enseignement et de recherche français ou étrangers, des laboratoires publics ou privés. 


\title{
Acoustic and diving behavior of sperm whales (Physeter macrocephalus) during natural and depredation foraging in the Gulf of Alaska
}

\author{
Delphine Mathias ${ }^{\mathrm{a})}$ and Aaron M. Thode \\ Marine Physical Laboratory, Scripps Institution of Oceanography, University of California San Diego, \\ La Jolla, California 92093-0238 \\ Jan Straley \\ University of Alaska Southeast, Sitka, Alaska 99835 \\ John Calambokidis and Gregory S. Schorr \\ Cascadia Research Collective, Olympia, Washington 98501 \\ Kendall Folkert \\ P.O. Box 6497, Sitka, Alaska 99835
}

(Received 13 September 2011; revised 25 April 2012; accepted 2 May 2012)

\begin{abstract}
Sperm whales have depredated black cod (Anoplopoma fimbria) from demersal longlines in the Gulf of Alaska for decades, but the behavior has recently spread in intensity and geographic coverage. Over a three-year period 11 bioacoustic tags were attached to adult sperm whales off Southeast Alaska during both natural and depredation foraging conditions. Measurements of the animals' dive profiles and their acoustic behavior under both behavioral modes were examined for statistically significant differences. Two rough categories of depredation are identified: "deep" and "shallow." "Deep depredating" whales consistently surface within $500 \mathrm{~m}$ of a hauling fishing vessel, have maximum dive depths greater than $200 \mathrm{~m}$, and display significantly different acoustic behavior than naturally foraging whales, with shorter inter-click intervals, occasional bouts of high "creak" rates, and fewer dives without creaks. "Shallow depredating" whales conduct dives that are much shorter, shallower, and more acoustically active than both the natural and deep depredating behaviors, with median creak rates three times that of natural levels. These results suggest that depredation efforts might be measured remotely with passive acoustic monitoring at close ranges.
\end{abstract}

(C) 2012 Acoustical Society of America. [http://dx.doi.org/10.1121/1.4726005]

PACS number(s): 43.80.Ka, 43.80.Nd [WWA]

Pages: 518-532

\section{INTRODUCTION}

\section{A. Background on sperm whale foraging and acoustic behavior}

Sperm whales (Physeter macrocephalus) are a cosmopolitan species distributed throughout the world's oceans (Whitehead, 2003; Berzin, 1971). While females and immature individuals generally reside at low latitudes, adult males also travel and forage at higher latitudes (Whitehead et al., 1992; Teloni et al., 2007). In the U.S., these whales are listed as an endangered species, but their current population in the North Pacific is unknown.

A deep-diving species, sperm whales regularly descend to depths greater than $400 \mathrm{~m}$ for periods ranging between 30 and $45 \mathrm{~min}$, and rest at the surface for periods ranging between 5 and $10 \mathrm{~min}$ (Papastavrou et al., 1989; Jaquet et al., 2001; Wahlberg, 2002; Watwood et al., 2006). The few data available from higher latitudes indicate shallower dive depths than what is measured in temperate or tropical latitudes (Whitehead et al., 1992; Teloni et al., 2007).

\footnotetext{
a) Author to whom correspondence should be addressed. Electronic mail: delphine.mathias@gmail.com
}

Sperm whales are vocally active underwater, and during a single dive an individual can generate thousands of impulsive sounds, called clicks (Goold et al., 1995; Worthington and Schevill, 1957; Madsen et al., 2002a; Wahlberg, 2002). Measurements in other regions of the world indicate that a whale typically falls silent about 10 to $15 \mathrm{~min}$ before it returns to the surface (Madsen et al., 2002a; Douglas et al., 2005; Watwood et al., 2006), so by passively monitoring an animal's vocalizations, its dive cycle can be estimated. In the Gulf of Alaska (GOA), click sounds from sperm whales have been detected throughout the year on bottom-mounted recorders, revealing a year-long presence in the region (Mellinger et al., 2004).

Another distinctive acoustic feature of sperm whales is the existence of "creak" (or "buzz") sounds, a sequence of pulses produced at a rate of 10 per second or faster (Madsen et al., 2002), and often characterized by a decrease in the pulse interval and (occasionally) amplitude over the 5-10 s duration of the sound (Whitehead and Weilgart, 1990; Whitehead, 2003). Teloni et al. (2007) and Miller et al. (2004) reported creak rates close to 15 creaks per hour. Watwood et al. (2006) reported that 37 sperm whales in the Atlantic Ocean, the Gulf of Mexico and the Ligurian Sea made $22 \pm 8.0$ creaks per hour. Previous bioacoustic tagging 
work on sperm whales has shown that most creaks occur at foraging depths and are often associated with changes in the orientation of the animal (Miller et al., 2004; Watwood et al., 2006). Creaks are often followed by a few seconds of silence before the animal resumes "usual" clicking (Madsen et al., 2002), defined here as a "creak-pause" event.

There are several possible interpretations of creak-pause events. One is that these intervals are used to recycle air within the sound production system (Wahlberg et al., 2002). Because creaks generally have lower received levels on hydrophones than usual clicks, it may also be possible that some clicks at the end of a creak become masked by noise, creating a false impression of silence. Another unproved hypothesis is that the silences are indicative of prey capture. Analogous signals observed in bats, dolphins, and beaked whales suggest that creaks are echolocation signals (Gordon, 1987; Madsen et al., 2002), and periods of time where creaks are detected have been described as prey capture attempts (Miller et al., 2004; Watwood et al., 2006). Laboratory studies on bat echolocation have found that post-buzz pause durations were longer after successful captures (Surlykke et al., 2003) than after unsuccessful attempts, but extending this conclusion to cetaceans is risky, as bats cannot produce sound when ingesting prey, while at least one cetacean species can (DeRuiter et al., 2009). Miller et al. (2004) found that the majority of creaks produced by sperm whales in the Ligurian Sea and the Gulf of Mexico are followed by pauses of about $5 \mathrm{~s}$. Beaked whales and porpoises often pause their echolocation for less than $2 \mathrm{~s}$ (Johnson et al., 2004, DeRuiter et al., 2009) and DeRuiter et al. (2009) found that porpoises ended creaks $0.8 \mathrm{~s}$ after prey capture, even though the animals are physiologically capable of echolocating and ingesting prey simultaneously. If this hypothesis is valid, then the presence of silences following creaks may permit the discrimination of successful prey capture attempts from unsuccessful ones on the basis of acoustic data obtained within a few kilometer range. Thus the duration of creaks, the rate at which they are produced, and the relative fraction of creaks that are followed by silence are all variables of interest in characterizing sperm whale acoustic dive behavior.

The diet of sperm whales generally consists of various cephalopod species, based on analyses of stomach contents (Okutani and Nemoto, 1964; Kawakami, 1980; Evans and Hindell, 2004). However, in certain regions fish seem to comprise an unknown fraction of the diet as well (Clarke, 1980; Kawakami, 1980; Whitehead, 2003), including the eastern Gulf of Alaska (Kawakami, 1980).

\section{B. Sperm whale depredation}

The question of the relative importance of fish to the sperm whale diet is a matter of practical concern, because sperm whales are known to take fish from fishing gear, a behavior known as "depredation." Although quantitative data are limited, sperm whale depredation appears to be increasing worldwide (Ashford et al., 1996; Capdeville, 1997; Nolan and Liddle, 2000; Purves et al., 2004). To date reports have been received from fishermen, engineers, fishery observers and biologists from Norway, Greenland, eastern Canada (Labrador and Newfoundland) and the Falkland Islands regarding interactions with sperm whales and bottlenose whales (Newfoundland only) in longline fisheries off these countries. Perez et al. (2006) estimated that marine mammal depredation on the combined longline fisheries in Alaska caused a loss of about $2.2 \%$ of the total fishery groundfish catch during 1998-2004, based on visual evidence of torn or partial fish.

In the eastern Gulf of Alaska (GOA) a demersal longline fishery for sablefish (Anoplopoma fimbria) occurs about 8.5 months a year. Sablefish (also called blackcod and butterfish) reside on the continental slope, and most commercial longliners operate in water depths between 400 and $1000 \mathrm{~m}$. The continental shelf off Kruzof, Baranof, and Chichagof islands, located near Sitka, AK, is very narrow; consequently, the sablefish grounds are within 12 miles of shore (see Fig. 1). A domestic sablefish survey in the GOA looked at catch rates from 1999-2001 for all sets with sperm whales present; they compared sets with and without physical evidence of depredation and found a 5\% lower catch rate in sets with depredation evidence (Sigler, 2008).

In 2003 the Southeast Alaska Sperm Whale Avoidance Project (SEASWAP) was created to investigate this issue with the long-term goal of reducing depredation. A collaborative study between fishermen, scientists and managers, SEASWAP works with the coastal fishing fleet to collect various quantitative data on longline depredation. Using the shape of the flukes as a unique identifier, SEASWAP found that at least 106 individual sperm whales have been involved in depredation. Bayesian mark-recapture analyses estimate at least 123 ([94-174]; 95\% credible interval) depredating whales in the GOA study area (Thode et al., 2006). The most ambitious SEASWAP field effort deployed eleven bioacoustic tags on sperm whales in 2007 and 2009, under both natural and depredation conditions off the continental shelf of Sitka, AK. The archival tags logged acoustic, depth, and orientation data.

In this paper these tag records are analyzed to address three issues. First, do natural foraging dives in Alaska differ from those measured from populations that rely primarily on cephalopods for their diet? Second, do acoustic behavioral parameters change significantly when the animals are depredating? To our knowledge few to no depredating marine mammals have ever been tagged before, and so the strategies employed by the animals are of interest, perhaps even suggesting mechanisms for reducing this behavior or its impact on the fishery. Finally, can passive acoustic monitoring be used to quantify depredation rates? Current methods rely on visual evidence at the surface, which is known to undercount depredation rates. A better "measuring stick" of depredation effort and/or success would be useful for evaluating the efficacy of future countermeasures.

\section{MATERIALS AND METHODS}

\section{A. Equipment}

The acoustic behavior, dive profiles, and spatial orientation of sperm whales were investigated using digital acoustic "B-probe" sampling tags (Burgess et al., 1998; Goldbogen et al., 2006; Johnson et al., 2009). Besides sampling acoustic 


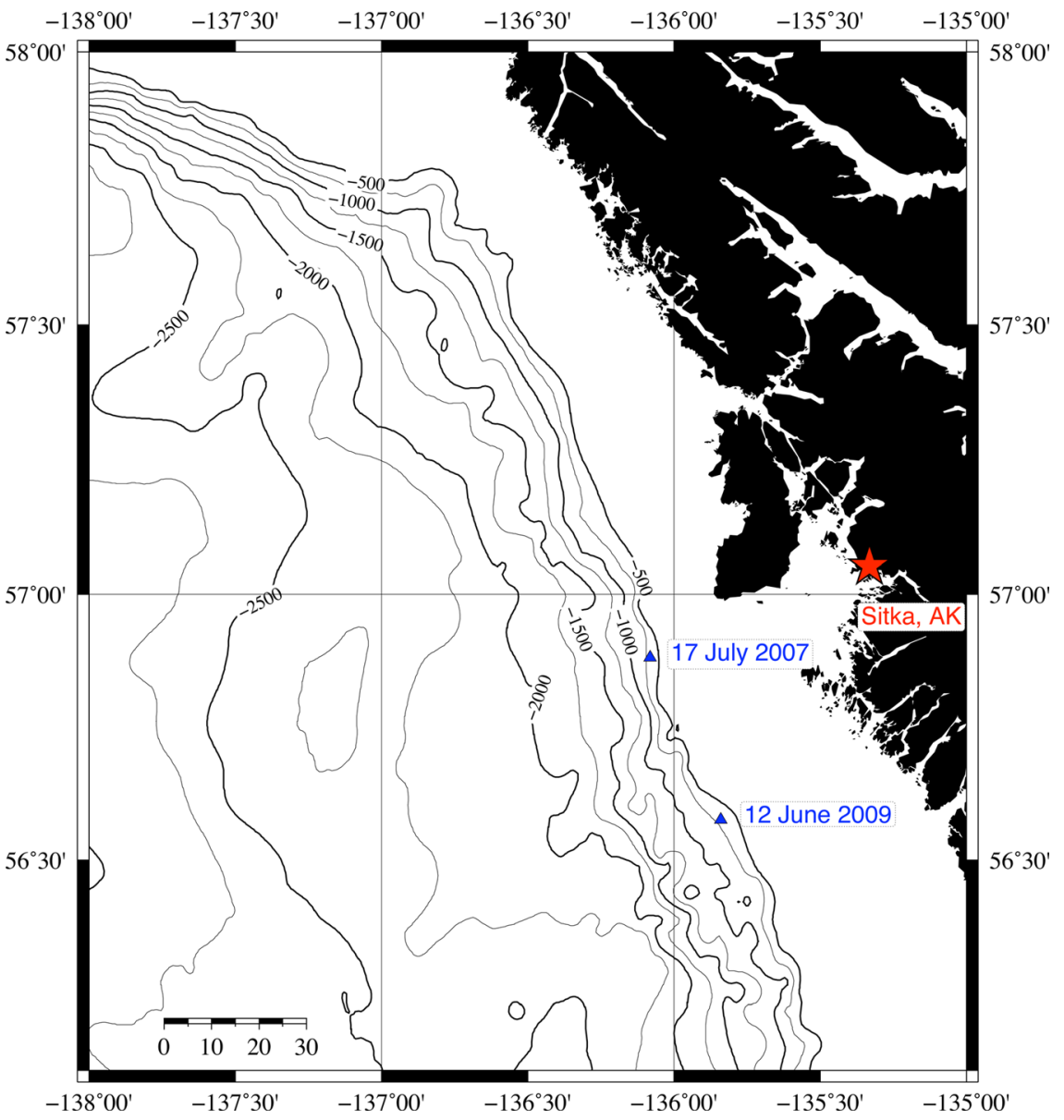

FIG. 1. (Color online) Local bathymetry off Sitka, AK, marked with fishing haul positions for the two tagging examples discussed in detail in Secs. III B and III C. Water depths are shown in meters.

data, the B-probe contains a pressure sensor and a two-axis accelerometer (MXA2500GL, Memsic, Inc., North Andover, MA 01845) with one axis parallel to the longitudinal axis of the probe. Data from the depth gauge and accelerometers are sampled at $1 \mathrm{~Hz}$ and stored within the tag. The acoustic signal was passed through a Linear Technologies LTC1164-6 switched-capacitor elliptic anti-aliasing filter before entering the analog-digital converter. The acoustic data analyzed in this paper were sampled at $4096 \mathrm{~Hz}$, sufficient for detecting regular clicks and creaks.

\section{B. Deployments and visual observation protocols}

The SEASWAP tagging effort used a 16 foot rigidhulled inflatable boat (RHIB), which mostly operated in the vicinity of cooperating fishing vessels in order to spot tagging opportunities. The two fishing vessels discussed in this paper include a small commercial fishing vessel ( $\mathrm{F} / \mathrm{V}$ Cobra, $18 \mathrm{~m}$ ), and a larger vessel (F/V Ocean Prowler, $38 \mathrm{~m}$ ) performing the NOAA Southeast Alaska sablefish survey. No other fishing vessels were within 15 miles of either vessel during the tagging studies discussed here, as confirmed by both the RHIB visual observations and radar monitoring by the F/V Cobra.

The tag was deployed from the RHIB using a modified windsurfing mast. Photographs were taken of the relative orientation of the tag on the animal. Once tagged, a whale was identified and followed via both visual sighting and monitoring the tag radio beacon. Whenever possible, further photographs of the tag placement were taken to note whether the relative orientation of the tag on the whale had shifted over time. No significant shifting of tag position was ever observed.

The tagging team was active mostly in the early morning, with the goal of deploying tags on animals before the start of a fishing haul. Once a haul began the tagging boat drifted away from the fishing vessel to avoid unduly influencing animal behavior. The visual observers noted times and distances of surfacing animals relative to the vessel, recorded subsequent orientation and surface movements, and noted times of "fluke ups," indicative of the start of a foraging dive. Photos were taken of most of the individuals surfacing within $500 \mathrm{~m}$ of the vessel. Individuals could then be identified by photo-ID, due to the presence of distinctive profiles, scars, and coloring on all sides of the whale. Distances were estimated by a laser range-finder, when possible; otherwise, the range was marked as being greater than or less than $500 \mathrm{~m}$ range from the vessel. Observers each day calibrated their visual distance determinations of $500 \mathrm{~m}$ with the laser range finder. The presence of an animal within $500 \mathrm{~m}$ of a vessel was used to help classify whether a whale was in a depredation or natural foraging state, for reasons to be described in Sec. II E.

\section{Dive profile analysis}

The pressure sensor data on the B-probe tags permitted recovery of dive profiles. The beginning and end of a given dive are defined as times when the animal's depth became 
deeper or shallower than $10 \mathrm{~m}$. Within each dive, a set of dive "inflections" are defined as points where the vertical velocity of the whale (the time derivative of the pressure) changed sign, consistent with the definitions used in Miller et al. (2004). After an inflection is noted, an ensuing net vertical change of at least $10 \mathrm{~m}$ (approximately $2 / 3$ of a typical body length) was required before a new inflection could be flagged.

The number of inflections logged during each dive was normalized by dividing the number of inflections in a dive by the total dive duration, yielding a rate of dive inflections per hour, or "Infl." The surface, bottom, and total dive durations $\left(T_{S}, T_{b}, T_{d}\right)$, as well as the maximum depth attained $\left(D_{\max }\right)$ were also extracted from each dive. The bottom time is measured from the end of the descent phase (the time when the pitch of the diving whale first rises above the horizontal plane) to the start of the ascent phase (the last point in time when the animal's pitch is below the horizontal plane), as defined in Miller et al. (2004).

\section{Acoustic data analysis}

Sperm whale "regular" clicks were automatically detected in the acoustic tag data by generating a series of 256 pt FFTs, overlapped $75 \%$, and then integrating the power spectral density between 1200 and $1900 \mathrm{~Hz}$. If a value exceeded a running-average estimate of background noise level by $20 \mathrm{~dB}$, the presence of a click was flagged; otherwise, the information was used to update the running average. The output of this automated click detector was manually spot-checked to confirm that clicks produced by other nearby non-tagged whales were not incorporated into the results.

Detecting creaks was more difficult, because their signal-to-noise ratio (SNR) is generally much lower. Creak sounds are almost always preceded by a set of regular clicks with steadily decreasing inter-click intervals (ICI), which eventually transition into the creak. During a creak the ICI decreases from 0.2 to $0.02 \mathrm{~s}$ (Gordon, 1987) and the creak amplitude decreases over time, with clicks at the end of a creak often $20 \mathrm{~dB}$ or more lower in level than at the beginning (Madsen et al., 2002).

Creak detection was semi-automated. The first step used automated click processing to note "gaps" in regular click trains, where a gap is defined as any pause between detected clicks between 5 and $60 \mathrm{~s}$ duration. Each gap was reviewed manually and aurally for the presence of a creak, and then categorized as a "silence," "creak-only," or "creak-pause" event. After a creak-only event, the whale began producing regular clicks within two seconds after the audible end of a creak, while creak-pause events contained at least two seconds of silence between the end of an audible creak and the resumption of a click train.

Special efforts were made to ensure that no creaks were missed due to the relatively low acoustic sampling rate $(4096 \mathrm{~Hz})$ of the tag. Whenever a gap was first categorized as silence but preceded by a decrease in the ICI of a regular click sequence, the sample was re-reviewed aurally and usually categorized as creak-only or creak-pause. Of the silent gaps generated by the automated detector that were preceded by a decrease in the regular click ICI, only $2 \%$ provided no aural evidence of a creak on further examination, and were thus categorized as true silence. Therefore, a steady decrease in the ICI of usual clicks proved to be a reliable indicator of an upcoming creak event.

To address the possibility that extended pauses after creaks arose from noise masking weak creaks, the duration of each creak was also estimated. The start time of the creak was defined as the when the ICI dropped below $0.2 \mathrm{~s}$, and the end time was defined as the start of a silent period of $2 \mathrm{~s}$ or longer duration.

Every tag record was decomposed into a set of dive profiles, with the beginning and end of each dive defined according to the criteria of the previous section. The following acoustic parameters were then extracted from each dive.

(a) Timing of first click $\left(T_{C l 1}\right)$ : the time difference in minutes between the start of a dive and when the first click is detected on the tag.

(b) Click rate $(\mathrm{Cl})$ : the total number of clicks produced during a dive, divided by the total dive duration in seconds. Clicks associated with creaks were excluded from the analysis. While in principle heavy bouts of creaking could also reduce this value, in reality creak rates were never high enough to reduce the click rate.

(c) Mean inter-click-interval (ICI): the mean interval in seconds between successive clicks within the same click train. Creak clicks (with intervals less than $0.2 \mathrm{~s}$ ) were excluded from this calculation. Note that ICI can differ from $\mathrm{Cl}$ if the whale is silent during substantial portions of the dive.

(d) Normalized creak-only $(\mathrm{Cr})$ and creak-pause $(\mathrm{CrP})$ rates: the number of a particular type of creak event produced during a dive, divided by the total dive duration in seconds.

(e) Fraction of creak-only $\left(F_{\mathrm{Cr}}\right)$ and creak-pause $\left(F_{\mathrm{CrP}}\right)$ events: the relative proportion of each creak event category for each dive.

\section{E. Behavioral categories and hypothesis testing}

The tag records were divided into four distinct behavioral categories, using the B-probe dive profile records, fluke photographs of tagged whales, and visual observations of sperm whale surface behavior. No acoustic or dive parameters (other than maximum dive depth) were used to assign a given dive to a category. The categories are defined as follows.

(1) Resting: behaviors characterized by shallow drifting and minimal changes in body orientation, regardless of whether a fishing vessel is hauling.

(2) Natural foraging: dives were conducted by animals at least $500 \mathrm{~m}$ from an actively hauling fishing vessel, or during times when the fishing vessel was not hauling gear. The distribution of estimated ranges of surfacing animals (using a laser-range finder or estimated visually as described in Sec. II B) generally clustered around $400 \mathrm{~m}$ or less, or at distances much greater than $500 \mathrm{~m}$. A visual 
range of $500 \mathrm{~m}$ was thus chosen to demarcate the natural and depredation categories.

If a tagged whale was visually identified consistently surfacing within $500 \mathrm{~m}$ of a hauling fishing vessel, then the subsequent dive was assigned to one of the following two categories.

(3) Deep depredation: Maximum dive depths are greater than $200 \mathrm{~m}$.

(4) Shallow depredation: Maximum dive depths are shallower than $200 \mathrm{~m}$.

A potential objection to this categorization scheme is that fishing vessels and naturally foraging whales might exploit the same productive locations, and thus these whales could randomly surface within $500 \mathrm{~m}$ of a hauling vessel. There is indeed evidence that depredation is more statistically likely to occur at more productive fishing spots (Straley, 2009); however, it is unlikely whales are surfacing close to the vessel by coincidence, for several reasons. First, experience has shown that sperm whales will generally not surface within $500 \mathrm{~m}$ of a fishing vessel before or after a haul, even if the vessel drifts for hours at the location of a fishing set. Just after a haul ends, a given whale will sometimes be sighted for one or two dives within $500 \mathrm{~m}$ of the vessel, but the range of the visual sightings always increases over time, unless the fishing vessel starts to maneuver or display other actions that may be associated with the beginning a of second haul.

Second, a hauling vessel generally travels 4-6 km laterally across the ocean floor when recovering longline gear, sometimes against the local current, but the same whales are consistently sighted within $500 \mathrm{~m}$ of the vessel during the entire haul. Thus the animals are diving in reference to the moving platform, and not in reference to some particular bathymetric feature, as might be expected were the whales simply exploiting a local "hot spot" of productivity.

Finally, the surface behavior of animals within $500 \mathrm{~m}$ of a hauling vessel is markedly different than that observed from a RHIB without a fishing vessel present. During a haul animals at the surface often orient their heads to point directly toward the vessel, often "dipping" their heads a slight amount underwater, while simultaneously generating bursts of clicks intense enough to be heard by a listener $1 \mathrm{~m}$ above the ocean surface. The cumulative impression left by these visual observations is that a whale consistently surfacing within $500 \mathrm{~m}$ of a hauling vessel should be assigned a different behavioral category than a whale surfacing during times when a haul is not occurring. The specific hypothesis examined in this paper is whether statistically significant differences in acoustic and diving behavior can be gleaned between categories initially defined by visual observations, vessel state, and maximum dive depth.

The distributions of the dive and acoustic parameters obtained for each category are non-Gaussian, often highly skewed, and characterized by large tails that indicate relatively infrequent but significant events that could not be discounted as outliers. Thus a two-sided Kolmogorov-Smirnov (KS) test was used to evaluate the probability that two sample parameter distributions, obtained from different behavioral categories, could have been drawn from the same underlying cumulative probability distribution. The null hypothesis is that various parameters measured from both behavioral categories were drawn from the same underlying distribution. A Bonferroni correction is applied to account for the number of dependent or independent statistical tests performed (Bonferroni, 1936). As ten parameters are tested for significant differences between behavioral categories, the $p$ value for an individual test is reduced to $0.05 / 10=0.005$. Thus, KS $p$-values of less than 0.005 led to the rejection of the null hypothesis at the $5 \%$ significance level.

Two KS tests were performed for each parameter of interest. The first test used all dives assigned to a given category, regardless of what individual produced the dive. The second test attempted to account for potential differences in individual behavior by only using tag records that contained both natural and depredation behaviors. The test then divides natural foraging dives into two categories: those occurring on a tag record associated with deep depredation states and those associated with shallow depredation states. No single tag record displayed both deep and shallow depredation states, so no ambiguity existed when assigning a dive to a category. The parameter distributions for shallow and deep depredating individuals are then compared with their associated natural foraging parameter distributions using the KS test. Differences in sample sizes between the categories are automatically incorporated into the two-sided KS test.

A potential objection to this method is that the data itself is used to define behavioral categories, so there could be a risk of correlation between the categories and the parameters tested for significant differences between them. However, only the distance between the fishing boat and a whale is used to define the whale state as "natural behavior" or "depredation behavior." Only the maximum depth of the whale is used to separate "deep depredation" and "shallow depredation" behaviors. All other dive and acoustic parameters are not used to define the categories.

\section{RESULTS}

\section{A. Summary of tag records}

Acoustic tags were deployed on sperm whales during two field efforts in July 2007 and June 2009. In 2007 eight B-probes recorded a total of $79 \mathrm{~h}$ of animal depth, orientation, and acoustic data. In 2009 three B-probes were deployed, generating $67 \mathrm{~h}$ of animal depth, orientation, and acoustic data. Thus over the course of two field seasons, seven distinct animals were successfully tagged 11 times with functioning B-probes, and all were matched with a photo-identification catalog. Two individuals were tagged twice in 2007, and one individual was tagged in both 2007 and 2009. The mean, median, and mode of the tag deployment times were 9.8, 7.0, and 9.0 h in 2007 and 22.3, 27.0, and 12.0 h in 2009.

A given tag record from a long deployment could contain several different behavioral states, and in the next two subsections two such tag records are reviewed in detail, collectively illustrating the four states defined in Sec. II E. Eight tag records had periods of natural foraging, documenting a total of 135 natural dives. Ten of the 11 whales tagged 
showed some degree of vessel association, in that the tagged animal consistently surfaced within $500 \mathrm{~m}$ of a hauling vessel. Seven of the ten tagged whales seen surfacing close to a longline fishing vessel displayed deep depredation behaviors, while the other three displayed shallow depredation behaviors. A total of 52 deep depredation dives and 35 shallow depredation dives were documented. Whales displaying shallow depredation also conducted a total of 64 natural dives, while the deep depredating whales also cumulatively displayed 66 natural dives. Three tags displayed 23 deep depredation dives with no natural foraging activity, and so these dives were excluded from the second KS test. The statistical differences between the diving and acoustic parameters of the behavioral categories, excluding resting behavior, are presented in Sec. III D.

\section{B. Resting, natural foraging, and deep depredation behaviors from a tag deployed on 12 June 2009}

This tag record is among the longest available (28 hours of data), and covers two complete fishing hauls. The whale displaying this tag record had been following the F/V Cobra since 11 June 2009, before being tagged close to the vessel at 13:53 on 12 June 2009. Subsequently the first longline haul began at 14:00 and ended four hours later. The vessel began its second haul the following day (13 June) at 11:15, finishing at 14:30. Visual observers sighted three whales during the first haul and six whales during the second haul, all consistently surfacing within $400 \mathrm{~m}$ of the vessel. Figure 2 displays the whale's dive profiles, along with each dive's assigned behavioral category, inflection rate, click rate, mean ICI, and total creak rate (both with and without subsequent pauses). With the exception of the maximum dive depth, none of the data shown in Fig. 2 were used to assign a dive to a particular behavioral category. The start and end of the fishing hauls are indicated by the solid and dotted vertical lines, respectively. A shaded area indicates that the tagged whale was sighted surfacing within $400 \mathrm{~m}$ of the fishing vessel for each shaded dive. The tag detached around 18:00 on 13 June.

At various times this whale displayed three of the four behavioral states defined in Sec. II E. The labeled horizontal bars in Fig. 2 indicate each state.

(1) Resting between 14:30 and 15:20 on 13 June, after completion of the second haul: the animal remains at less than $30 \mathrm{~m}$ depth, and its inflection rate, creak rate, and click rate are at levels much lower than natural foraging conditions.

(2) Natural foraging behavior between 18:00 on 12 June and 11:25 on 13 June, and between 15:20 and 18:00 on 13 June: the animal shows considerable variation in dive depth, with the dive profiles systematically shallowing and deepening between 250 and $750 \mathrm{~m}$ throughout the night and morning. The normalized creak rate also varies between 5 and 20 creaks/h. During the natural foraging state $54 \%$ of creaks detected $\left(F_{C \mathrm{rP}}\right)$ were followed by distinctive pauses.

(3) Deep depredation during both hauls: during the first haul, all depth and acoustic behaviors displayed by the animal lie within the range of normal foraging behavior, with the exception of a high creak rate of over $30 \mathrm{creaks} / \mathrm{h}$ for one dive. During this phase $43 \%$ of detected creaks were followed by distinctive pauses. During the second haul, the animal's depth range and usual click parameters also lay within normal bounds; however, the dive inflection rate is slightly greater than average, and the creak rate attains or exceeds $30 \mathrm{creaks} / \mathrm{h}$ through half the haul, then drops off to nothing for one dive. Only $30 \%$ of creaks were followed by distinctive pauses. The ICI seems similar during both natural and depredation states.

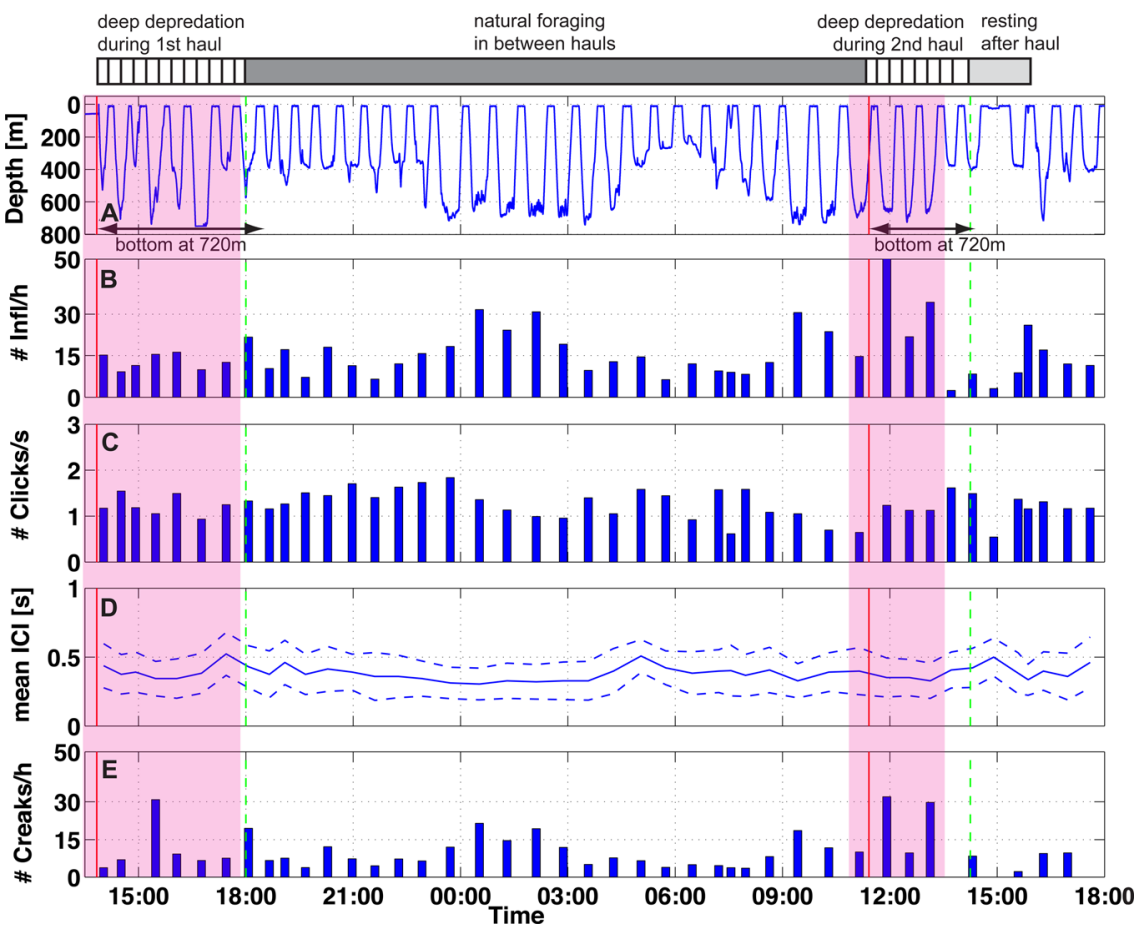

FIG. 2. (Color online) Selected dive and acoustic parameters of a whale displaying resting, natural foraging behavior and deep depredation behavior on 12 June 2009: (a) dive profile; (b) normalized dive inflection rate per hour, Infl, with each bar representing a distinct dive; (c) click rate per second, $\mathrm{Cl}$; (d) mean inter-clickinterval ICI per dive, with dotted lines corresponding to one standard deviation; and (e) normalized creak rate per hour, combining creakonly and creak-pause events. The start and end times of the fishing hauls are indicated by the solid and dotted vertical lines, respectively. The shaded areas indicate when the tagged whale was visually sighted surfacing within $400 \mathrm{~m}$ of the F/V Cobra for every dive. 
The water depth at both haul locations was $720 \mathrm{~m}$, so the tagged whale sometimes dove all the way down to the ocean floor during deep depredation. The timing of dive inflections and timing of creaks is highly correlated, with a correlation coefficient of 0.78 .

\section{Natural foraging behavior and shallow depredation from a tag deployed on 17 July 2007}

On 17 July 2007 a whale was tagged at 7:50, close to the F/V Ocean Prowler, which was deploying two longline sets at $690 \mathrm{~m}$ water depth. The vessel began hauling its first longline set at 10:00, ending at 12:50, and then began hauling its second longline set at 13:30, ending at 18:00. A total of four whales surfaced within $500 \mathrm{~m}$ of the Prowler throughout both hauls, with the tagged whale consistently surfacing between 150 and $400 \mathrm{~m}$ astern of the Prowler during the hauls. After 17:30 the whale was sighted swimming away from the vessel, and by the end of the haul it was at least $2 \mathrm{~km}$ away.

Figure 3 displays the whale's dive statistics in a format identical to that of Fig. 2. Between 7:50 and 10:00 the whale's dives became gradually shallower and less regular in terms of surface and dive durations. During both hauls, the whale performed shallow and irregular dives $(120 \pm 83 \mathrm{~m})$. Between the end of the first haul and the start of the second, the whale made a $37 \mathrm{~min}$ dive down to $510 \mathrm{~m}$. At 17:00, $30 \mathrm{~min}$ before the end of the second haul, the whale's dives became deeper and more regular in terms of surface and dive duration. From 18:00 until the tag released the whale alternated $28 \mathrm{~min}$ dives down to a median depth of $350 \mathrm{~m}$ with 11 min surface times.

During the shallow depredation state multiple dive parameters show significant differences from the other behavioral states. For example, during the haul depths are shallow (less than $200 \mathrm{~m}$ ) compared to the remainder of the tag record (deeper than $300 \mathrm{~m}$ ). During shallow depredation inflection rates are higher by a factor of 2 , click rates are six times higher, the mean ICI is smaller, and creak rates are 10 times higher. During shallow depredation $65 \%$ of all creaks were subsequently followed by silence (i.e., creak-pause events). Only three natural dives before and after the haul displayed creak sounds, with a creak-pause fraction of $47 \%$, and click rates are very low, with minutes of time elapsing without the animal making a sound at depth. The timing of dive inflections and timing of creaks had a correlation coefficient of 0.71 .

\section{Comparison of behavioral states across all tag records}

Figures 4 and 5 display the dive and acoustic parameter distributions compiled from all 11 tag records. Each figure contains five subplots, corresponding to the parameters defined in Secs. II C and II D. Each subplot shows three box plots corresponding to the natural foraging, deep depredation, and shallow depredation categories. Figure 5(e) also displays the creak-pause fractions measured by other biotagging studies in temperate latitudes (Miller et al., 2004). Tables I and II summarize the mean and standard deviations of these distributions, along with the $p$ values of the two-sample KS nonparametric tests. $p$-values less than 0.005 are italicized.

Figures 6 and 7 use the same format as Figs. 4 and 5, but here only data from tag records that display both natural and depredation behaviors are used. Two box plots for natural foraging behavior are now shown: one for dives preceding or following deep depredation, and one for dives preceding or following shallow depredation. The box plots thus show distributions drawn from the same pools of individuals, thus reducing potential individual variations in dive or acoustic behavior. Differences in sample sizes between the categories are automatically incorporated into the two-sided KS test.

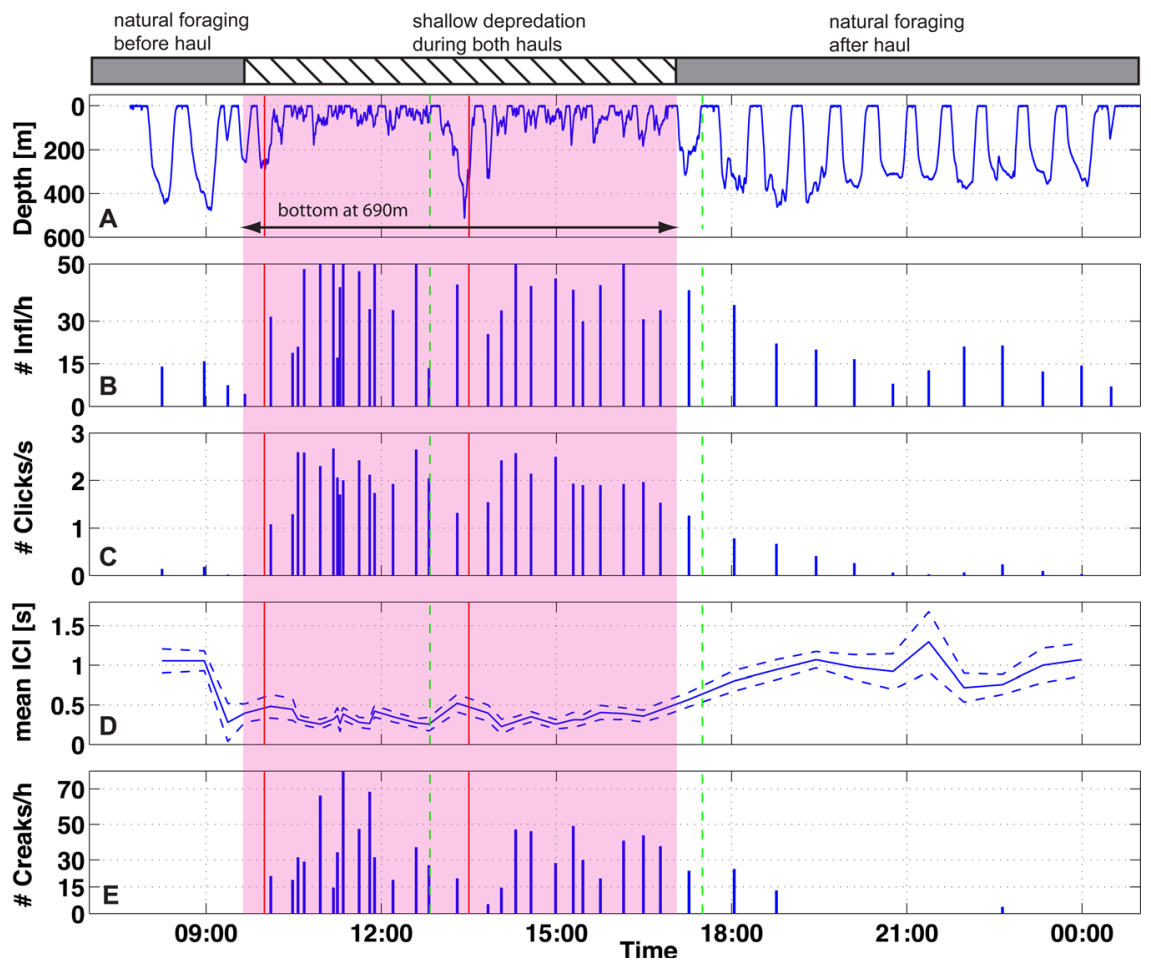

FIG. 3. (Color online) Tag parameters of a whale displaying natural foraging and shallow depredation behavior on 17 July 2007, using the same format as Fig. 2. The shaded area indicates when the surfacing whale was visually sighted within $400 \mathrm{~m}$ of the F/V Prowler. 

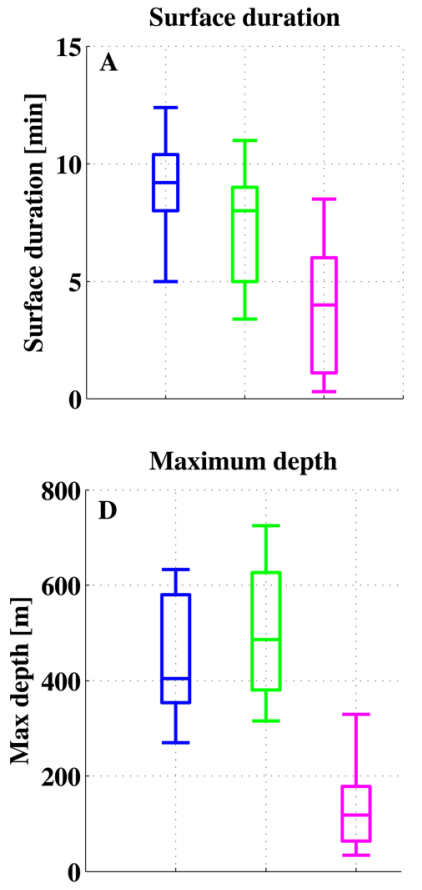
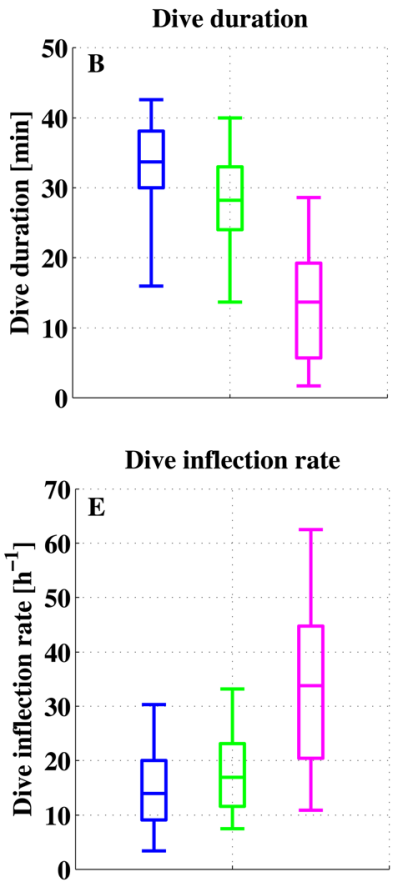
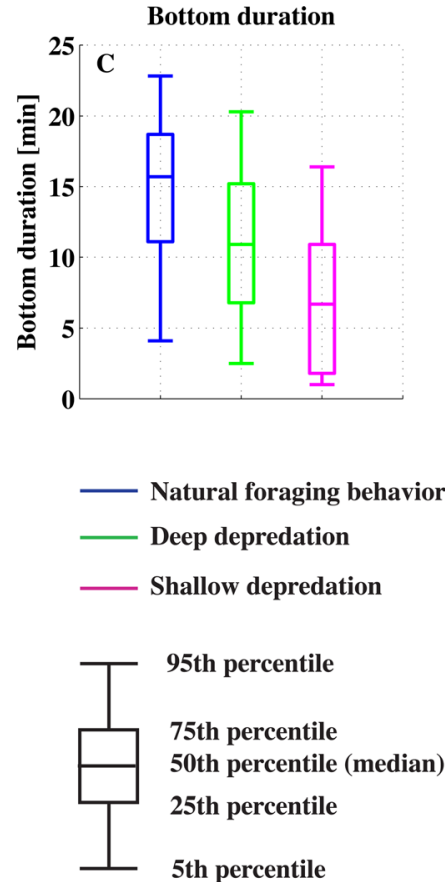

FIG. 4. (Color online) Boxplots of five dive parameter distributions, obtained from all tag records, subdivided by behavioral state: (a) surface duration (min); (b) dive duration ( $\mathrm{min}) ;(\mathrm{c})$ bottom duration (min); (d) maximum dive depth (m); and (e) normalized dive inflection rate per hour. These parameters are defined in Sec. II C. The box plots show the 5 th, 25th, 50th, 75th, and 95th percentile values of the distributions.
Tables III and IV display the results of the KS analysis on the distributions shown in Figs. 6 and 7, with the $p$-values indicating the result of comparing a particular depredation category with natural foraging dives preceding or following that type of depredation.

\section{DISCUSSION}

\section{A. Is natural foraging behavior off Sitka similar to elsewhere in the world?}

A distinctive feature of sperm whale behavior is the depths of their foraging dives. Although aspects of the diving, acoustic and body motion behavior of male sperm whales have been studied at both low (Gordon, 1987; Whitehead et al., 1991; Watwood et al., 2006) and high latitudes (Whitehead et al., 1992; Jaquet et al., 2001; Madsen et al., 2002; Douglas et al. 2005; Teloni et al., 2007), no data have been published for the Gulf of Alaska area. A question that arises is whether dive and acoustic parameters of the Alaskan whales under natural foraging conditions are consistent with measurements obtained elsewhere. Male sperm whales in this study dove to mean maximum depths of $438 \mathrm{~m}$ (Table I) when displaying natural foraging behavior, with maximum dive depths of around $800 \mathrm{~m}$. Thus most dives did not descend to the ocean floor, and the observed dive and surface durations [Figs. 4(a) and 4(b)] are similar to the ones reported in another
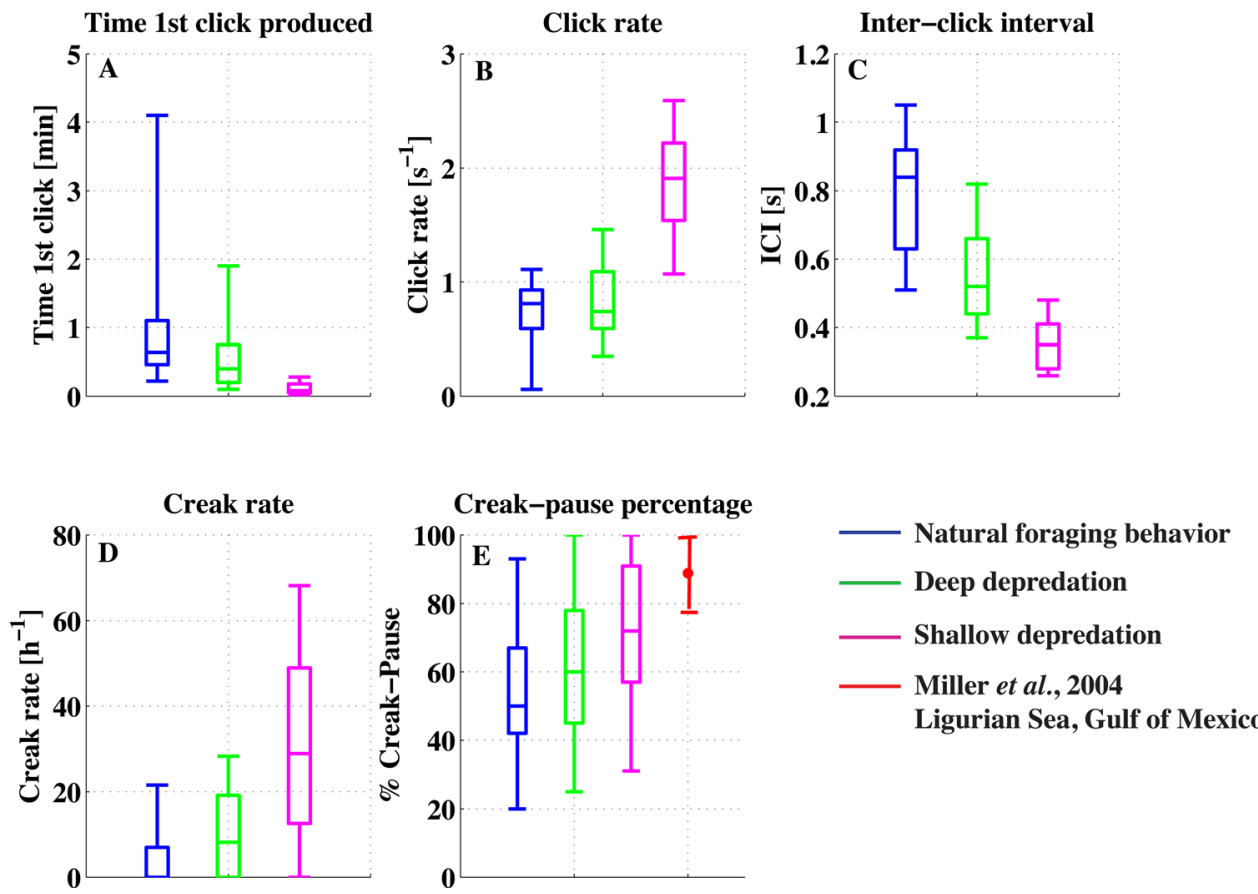

FIG. 5. (Color online) Boxplots of five acoustic parameter distributions, obtained from all tag records, subdivided by behavioral state: (a) time of first click produced (min), relative to start of dive; (b) click rate per s; (c) inter-click interval (s); (d) normalized creak rate per hour (for all creak events); and (e) creak-pause percentage. These parameters are defined in Sec. II D. The box plots show the 5th, 25th, 50th, 75th, and 95th percentile values of the distributions. 
TABLE I. Dive statistics for 2007 and 2009 data. Values are means $+/-$ s.d. over the number of dives $N_{d}$ considered. $N_{\text {tag }}$ corresponds to the number of tag records displaying each behavior. $N_{\text {ind }}$ corresponds to the number of individuals displaying each behavior. A $p$-value is the probability that the distribution is drawn from the same distribution as the natural foraging distribution. Italic $p$-values indicate the rejection of the null-hypothesis of a common underlying distribution $(p<0.005)$.

\begin{tabular}{|c|c|c|c|c|c|c|c|c|}
\hline & $\begin{array}{l}D_{\max } \\
(\mathrm{m})\end{array}$ & $\begin{array}{c}T_{s} \\
(\mathrm{~min})\end{array}$ & $\begin{array}{c}T_{d} \\
(\min )\end{array}$ & $\begin{array}{c}T_{b} \\
(\mathrm{~min})\end{array}$ & $\begin{array}{c}\text { Infl } \\
\left(\mathrm{h}^{-1}\right)\end{array}$ & $N_{d}$ & $N_{\text {tag }}$ & $N_{\text {ind }}$ \\
\hline Resting & $31.7+/-3.5$ & $6.1+/-0.6$ & $15.9+/-2.3$ & $7.1+/-1.6$ & $5.0+/-1.8$ & 10 & 3 & 3 \\
\hline Natural foraging & $438.5+/-135.0$ & $8.9+/-2.2$ & $33.0+/-7.9$ & $14.5+/-5.9$ & $15.2+/-8.2$ & 135 & 8 & 6 \\
\hline Deep depredation & $\begin{array}{c}487.2+/-160.4 \\
p=0.02\end{array}$ & $\begin{array}{c}7.4+/-2.4 \\
p<0.005\end{array}$ & $\begin{array}{c}28.4+/-9.4 \\
p \ll 0.005\end{array}$ & $\begin{array}{c}11.7+/-6.2 \\
p<0.005\end{array}$ & $\begin{array}{c}19.1+/-10.8 \\
p=0.03\end{array}$ & 52 & 7 & 5 \\
\hline Shallow depredation & $\begin{array}{c}145.1+/-108.2 \\
p \ll 0.005\end{array}$ & $\begin{array}{c}3.9+1-2.6 \\
p \ll 0.005\end{array}$ & $\begin{array}{c}13.8+/-8.9 \\
p \ll 0.005\end{array}$ & $\begin{array}{c}7.1+/-5.0 \\
p \ll 0.005\end{array}$ & $\begin{array}{c}35.1+/-16.9 \\
p \ll 0.005\end{array}$ & 35 & 3 & 3 \\
\hline
\end{tabular}

high-latitude study (Teloni et al., 2007). That same study also reported natural dives shallower than $200 \mathrm{~m}$ off Norway, but there has been no indication that sperm whales in this study naturally perform such shallow dives. In our study area in the eastern Gulf of Alaska, off Sitka, naturally foraging male sperm whales spent $85 \%$ of their total dive time emitting usual clicks, generally starting within $1 \mathrm{~min}$ of the descent phase and stopping early during the ascent phase. The mean depths of their first creaks were shallower $(80 \mathrm{~m})$ than the mean depths of the last creaks $(300 \mathrm{~m})$, suggesting that the whales were not searching for prey items during the ascent phase. These results are similar to what has been reported in other studies (Madsen et al., 2002; Douglas et al., 2005; Watwood et al., 2006). The click and creak rates, as well as the ICI values, reported in Figs. 5(b)-5(d) lie within the ranges reported by Miller et al. (2004) at low latitudes and by Teloni et al. (2007) off Norway.

Miller et al. reported that while foraging at depth, 22 sperm whales from the Ligurian Sea and the Gulf of Mexico made $12.5 \pm 4.0$ dive inflections per hour, and a mean of $32 \%$ of all creaks were produced within $10 \mathrm{~s}$ of a dive inflection. The sperm whales in this study made $15.2 \pm 8.2$ dive inflections per hour [Fig. 4(e)], and consistent relationships were also found between the timing of dive inflections and creak events: $85 \%$ of creaks started within $30 \mathrm{~s}$ of a dive inflection, and 56\% started within $10 \mathrm{~s}$ of a dive inflection. Three of the 11 tagged whales displayed a total of 10 resting dives, all of them being "head-down" drift-dives. The durations of those resting dives $(15.9 \pm 2.3 \mathrm{~min})$ and the depths at which they occurred $(31.7 \pm 3.5 \mathrm{~m})$ are consistent with those reported in Miller et al. (2008). Thus dive parameters from naturally foraging sperm whales in the eastern Gulf of
Alaska are within the bounds measured at other regions around the world.

However, two significant differences in natural acoustic behavior were found. First, 50\% of dives were not associated with any creaks [Fig. 5(d)], which is higher than what Teloni et al. (2007) reported (15\%). Second, the relative proportion of creak-pause events $\left(F_{\mathrm{CrP}}\right)$ is $48.4 \% \pm 10.2$ in Fig. 5(e), which is considerably lower than the only other published description of this fraction $(88.9 \% \pm 13.5)$, in Miller et al. (2004). The potential relevance of these differences is examined in Sec. IV B 3.

\section{B. Depredation vs natural foraging behavior}

\section{Dive parameters during shallow depredation}

Three of the ten tagged whales seen surfacing close to a hauling longline fishing vessel had dives assigned to the shallow depredation category. Figures 4 and 6 demonstrate how this category is substantially different from the other categories across all dive parameters. The maximum dive depths of animals during this state were generally much shallower than those of naturally foraging whales [Fig. 4(d)]. The surface, dive, and bottom durations were also much shorter than the corresponding natural durations in Figs. 4(a)-4(c) and 6(a)-6(c). The contrast in bottom duration time is particularly striking in that tagged whales displaying shallow depredation generally conducted longer natural dives, when compared with the natural bottom time distribution for deep depredating animals [Fig. 6(c), second box plot]. Finally, dive inflection rates were twice as high during shallow depredation than during natural situations. Given the strong visual contrasts in the dive parameter distributions in Figs. 4 and 6, it is not

TABLE II. Acoustic statistics for 2007 and 2009 data. Values are means $+/-$ s.d. over the number of dives $N_{d}$ considered. A $p$-value is the probability that the distribution is drawn from the same distribution as the natural foraging distribution. Italic $p$-values indicate the rejection of the null-hypothesis of a common underlying distribution $(p<0.005)$.

\begin{tabular}{|c|c|c|c|c|c|}
\hline & $\begin{array}{l}T_{\mathrm{C} 11} \\
(\mathrm{~m})\end{array}$ & $\begin{array}{c}C l \\
\left(\mathrm{~s}^{-1}\right)\end{array}$ & $\begin{array}{l}I C I \\
(\mathrm{~s})\end{array}$ & $\begin{array}{c}C r+C r P \\
\left(\mathrm{~h}^{-1}\right)\end{array}$ & $\begin{array}{l}F_{\mathrm{CrP}} \\
(\%)\end{array}$ \\
\hline Resting & N/A & N/A & N/A & N/A & N/A \\
\hline Natural foraging & $0.9+/-0.3$ & $0.7+/-0.2$ & $0.8+/-0.2$ & $7.9+/-4.6$ & $48.4+/-10.2$ \\
\hline Deep depredation & $\begin{array}{c}0.5+/-0.4 \\
p=0.03\end{array}$ & $\begin{array}{c}0.8+/-0.3 \\
p=0.08\end{array}$ & $\begin{array}{c}0.4+/-0.1 \\
p \ll 0.005\end{array}$ & $\begin{array}{c}11.3+/-7.1 \\
p<0.005\end{array}$ & $\begin{array}{c}58.4+/-13.0 \\
p=0.08\end{array}$ \\
\hline Shallow depredation & $\begin{array}{c}0.1+/-0.1 \\
p<0.005\end{array}$ & $\begin{array}{c}1.9+/-0.4 \\
p \ll 0.005\end{array}$ & $\begin{array}{c}0.3+/-0.1 \\
p \ll 0.005\end{array}$ & $\begin{array}{c}34.5+/-15.2 \\
p \ll 0.005\end{array}$ & $\begin{array}{c}68.3+/-16.4 \\
p=0.04\end{array}$ \\
\hline
\end{tabular}



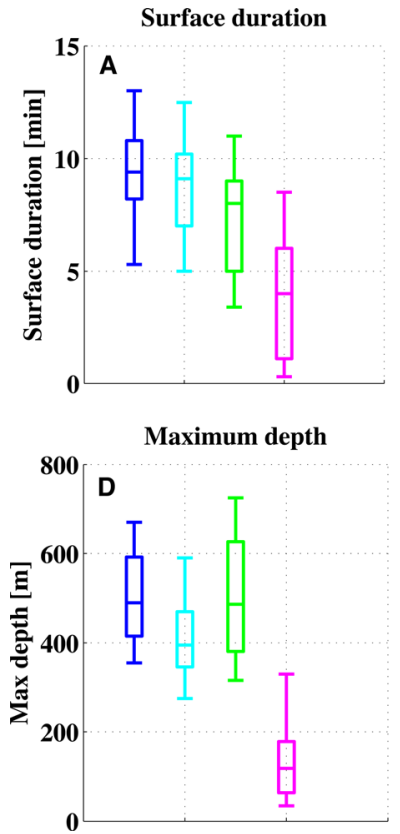
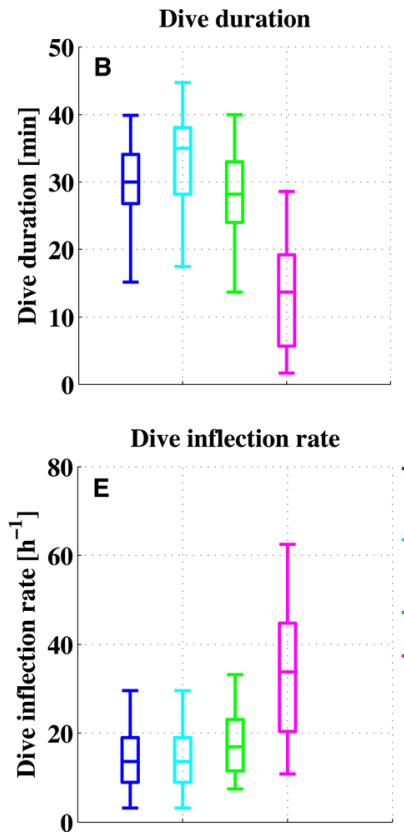

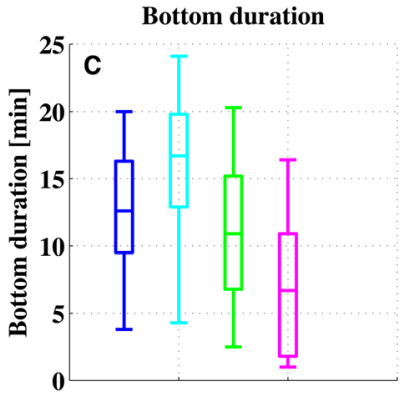

_ Natural foraging behavior associated with deep depredation

_ Natural foraging behavior associated with shallow depredation

— Deep depredation

Shallow depredation
FIG. 6. (Color online) Boxplots of same dive parameters shown in Fig. 4 , but only using tag records that display both natural and depredation behavior. For each parameter, distributions are shown for deep and shallow depredation states, along with the distributions for the natural foraging states preceding/following a given depredation behavior. The box plots show the 5 th, 25th, 50th, 75th, and 95th percentile values of the distributions. surprising that the $\mathrm{KS}$ tests yield highly significant $p$-values for all dive parameters (Tables I and III).

\section{Dive parameters during deep depredation}

The seven other tagged whales seen surfacing consistently next to a fishing vessel were assigned to the deep depredation category. The differences between deep depredation and natural diving behavior were subtler than for shallow depredation. Deep-depredating whales had shorter surface, dive, and bottom durations when compared to the complete distribution of natural foraging samples [Figs. 4(a)-4(c)]; however, when the natural foraging dive samples were restricted to tag records displaying deep depredation only, the differences became much smaller, except for the surface duration [Fig. 6(a)]. The KS tests of the distributions in Fig. 6 (Tables I and III) still showed statistically significant differences for surface and dive durations.

At first glance Fig. 4(d) suggests that depredation dives were slightly deeper than natural foraging dives; for example, $40 \%$ of deep-depredation dives exceeded $600 \mathrm{~m}$ vs only $15 \%$ of all natural foraging dives. But when the natural dive samples were restricted to those conducted by deep depredating whales only [Fig. 6(d)], one found little visible difference between the maximum dive depths, and the $p$-value for that analysis was not significant $(p=0.04)$. The dive inflection rate distribution varied little between natural foraging and deep depredation and was not statistically significant.

Interestingly, two of the ten depredating whales also performed either one or two resting dives, just before or after
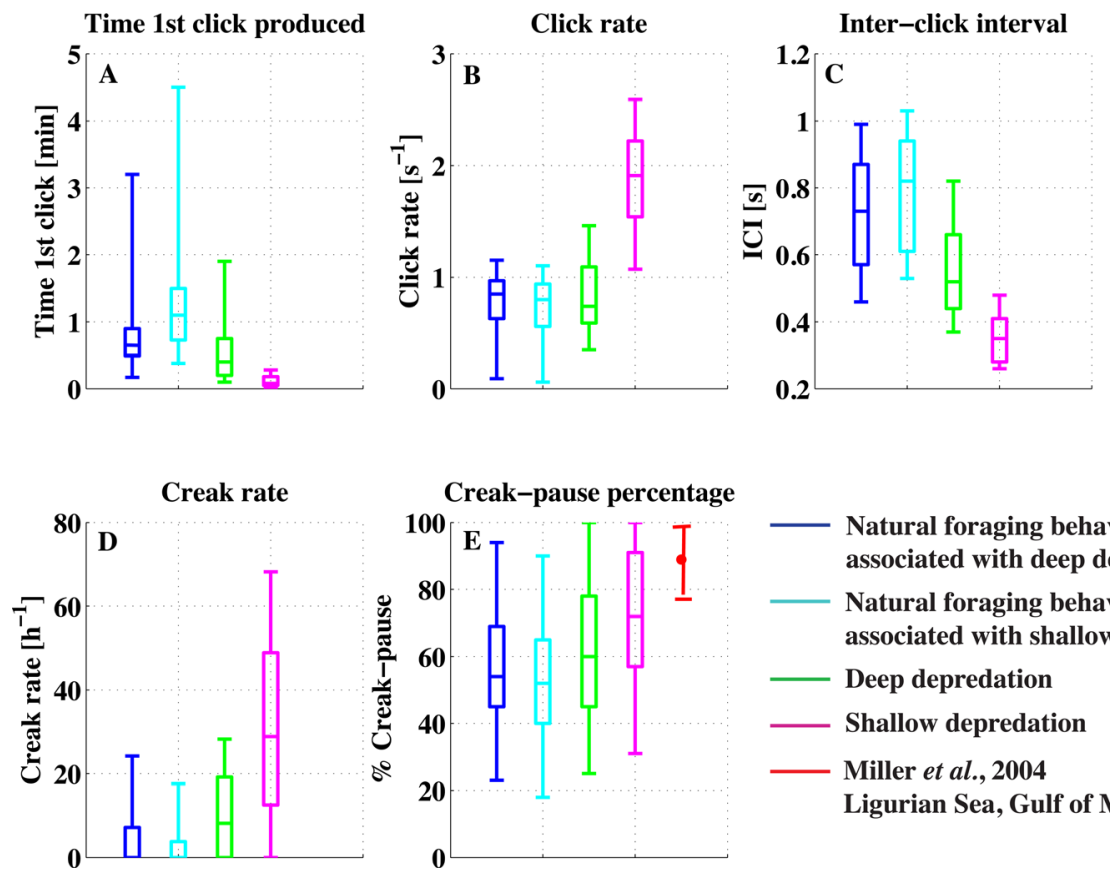

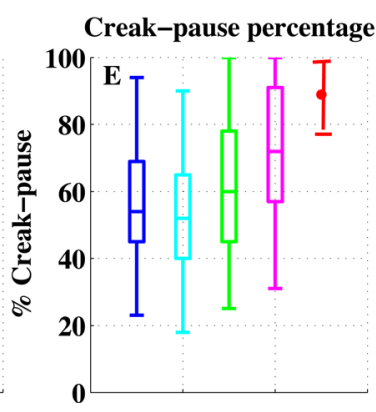

FIG. 7. (Color online) Boxplots of same acoustic parameters shown in Fig. 5, but only using tag records that display both natural and depredation behavior. For each parameter, distributions are shown for deep and shallow depredation states, along with the distributions for the natural foraging states preceding/following a given depredation behavior. The box plots show the 5th, 25th, 50th, 75 th, and 95 th percentile values of the distributions. 
TABLE III. Dive statistics for 2007 and 2009 data, comparisons within same tag record only. Values are means $+/-$ s.d. over the number of dives $N_{d}$ considered. $N_{\text {tag }}$ corresponds to the number of tag records displaying each behavior. $N_{\text {ind }}$ corresponds to the number of individuals displaying each behavior. A $p$-value is the probability that the distribution is drawn from the same distribution as the natural foraging distribution. Italic $p$-values indicate the rejection of the null-hypothesis of a common underlying distribution $(p<0.005)$.

\begin{tabular}{|c|c|c|c|c|c|c|c|c|}
\hline & $\begin{array}{l}D_{\max } \\
(\mathrm{m})\end{array}$ & $\begin{array}{l}T_{s} \\
(\mathrm{~min})\end{array}$ & $\begin{array}{c}T_{d} \\
(\min )\end{array}$ & $\begin{array}{c}T_{b} \\
(\mathrm{~min})\end{array}$ & $\begin{array}{l}\text { Infl } \\
\left(\mathrm{h}^{-1}\right)\end{array}$ & $N_{d}$ & $N_{\text {tag }}$ & $N_{\text {ind }}$ \\
\hline Resting & $31.7+/-3.5$ & $6.1+/-0.6$ & $15.9+/-2.3$ & $7.1+/-1.6$ & $5.0+/-1.8$ & 10 & 3 & 3 \\
\hline Natural foraging associated with deep depredation & $481.6+/-152.7$ & $9.2+/-2.5$ & $30.0+/-7.7$ & $12.6+/-5.0$ & $15.6+/-7.0$ & 66 & 4 & 2 \\
\hline Natural foraging associated with shallow depredation & $417.4+/-119.3$ & $8.9+/-2.0$ & $35.0+/-8.1$ & $16.7+/-8.3$ & $14.8+/-9.3$ & 64 & 3 & 3 \\
\hline Deep depredation & $\begin{array}{c}487.2+/-160.4 \\
p=0.04\end{array}$ & $\begin{array}{c}7.4+1-2.4 \\
p<0.005\end{array}$ & $\begin{array}{c}28.4+1-9.4 \\
p<0.005\end{array}$ & $\begin{array}{c}11.7+/-6.2 \\
p=0.04\end{array}$ & $\begin{array}{c}19.1+/-10.8 \\
p=0.05\end{array}$ & 29 & 4 & 2 \\
\hline Shallow depredation & $\begin{array}{c}145.1+/-108.2 \\
p \ll 0.005\end{array}$ & $\begin{array}{c}3.9+1-2.6 \\
p \ll 0.005\end{array}$ & $\begin{array}{c}13.8+/-8.9 \\
p \ll 0.005\end{array}$ & $\begin{array}{c}7.1+/-5.0 \\
p \ll 0.005\end{array}$ & $\begin{array}{c}35.1+/-16.9 \\
p \ll 0.005\end{array}$ & 35 & 3 & 3 \\
\hline
\end{tabular}

a series of shallow or deep depredating dives. Those resting dives thus happened in the middle of the day, while resting dives observed during natural foraging behavior usually happened during the night. This suggests that depredating dives might be more energy consuming than normal foraging dives, that depredating animals become satiated and can rest before resuming natural feeding, and/or that whales might rest while waiting for the start of a haul.

\section{Acoustic parameters during shallow depredation}

Shallow depredating animals were very active acoustically, when compared with natural foraging behavior (Figs. 5 and 7, Tables II and IV). They continuously produced usual clicks, even when resting at the surface, and they began clicking almost immediately after starting a dive [Figs. 5(a) and 7(a)]. Their median click rate was nearly double over that displayed by naturally foraging dives; the reason for this difference is that the inter-click interval during shallow depredation was much smaller; over $75 \%$ of clicks during this behavior had an ICI less than 0.4, an interval never observed during natural behavior. Similar patterns arose for creak production rates; the median creak rate of 30 creaks/h during shallow depredation was more than three times higher than natural creak rates. The spread in creak rate values was also very high during shallow depredation: the 25 th and 75 th percentiles lie between 10 and 50 creaks per hour, respectively, while the spread was much narrower for natural dives. There was much less dramatic change in the median percentage of creak-pause events during shallow depredation; however,
Fig. 5(e) shows that $75 \%$ of dives had creak-pause percentages exceeding $58 \%$, while only $40 \%$ of natural foraging dives exceeded this fraction. Figure 7(e) shows that this difference persisted even when the natural foraging dives were restricted to individuals that also display shallow depredation. However, the large spread in the creak-pause percentage distributions under both behavioral conditions resulted in a nonsignificant $p$-value from the KS test (0.04), the only acoustic parameter for shallow depredation not to differ significantly from natural behavior.

Shallow depredation dives showed another interesting acoustic effect, in that both click and the creak rates are generally lower during natural foraging dives that occurred after a haul is completed (e.g., Fig. 3). One possible interpretation of this result is that whales become satiated or tired after shallow depredation.

\section{Acoustic parameters during deep depredation}

The acoustic behavior of deep depredating whales showed significant differences from natural foraging behavior as well. One noticeable behavioral shift was that deep depredating whales displayed significantly shorter ICIs (median $0.5 \mathrm{~s}$ ) vs a median value of $0.75 \mathrm{~s}$ for the same individuals during natural dives [Fig. 7(c)] and a median value of $0.85 \mathrm{~s}$ for all natural foraging dives from all individuals. The KS test confirmed that a shift in the ICI distribution was the most significant effect (lowest $p$-value). Surprisingly, the average click rate of deep depredating whales did not change significantly, despite the noticeable shift in ICI levels. In

TABLE IV. Acoustic statistics for 2007 and 2009 data, comparisons within same tag record. Values are means $+/-$ s.d. over the number of dives $N_{d}$ considered. A $p$-value is the probability that the distribution is drawn from the same distribution as the natural foraging distribution. Italic $p$-values indicate the rejection of the null-hypothesis of a common underlying distribution $(p<0.005)$.

\begin{tabular}{|c|c|c|c|c|c|}
\hline & $\begin{array}{r}T_{\mathrm{Cl1}} \\
(\mathrm{m})\end{array}$ & $\begin{array}{c}C l \\
\left(\mathrm{~s}^{-1}\right)\end{array}$ & $\begin{array}{l}I C I \\
(\mathrm{~s})\end{array}$ & $\begin{array}{c}C r+C r P \\
\left(\mathrm{~h}^{-1}\right)\end{array}$ & $\begin{array}{r}F_{\mathrm{CrP}} \\
(\%)\end{array}$ \\
\hline Resting & N/A & N/A & N/A & N/A & N/A \\
\hline Natural foraging associated with deep depredation & $0.6+/-0.2$ & $0.8+/-0.2$ & $0.6+/-0.2$ & $8.7+/-4.9$ & $53.9+/-9.3$ \\
\hline Natural foraging associated with shallow depredation & $1.2+/-0.3$ & $0.7+/-0.3$ & $0.8+/-0.1$ & $6.3+/-3.5$ & $46.7+/-7.0$ \\
\hline Deep depredation & $\begin{array}{c}0.5+/-0.4 \\
p<0.005\end{array}$ & $\begin{array}{c}0.8+/-0.3 \\
p=0.2\end{array}$ & $\begin{array}{c}0.4+/-0.1 \\
p \ll 0.005\end{array}$ & $\begin{array}{c}11.3+/-7.1 \\
p \ll 0.005\end{array}$ & $\begin{array}{c}58.4+/-13.0 \\
p=0.07\end{array}$ \\
\hline Shallow depredation & $\begin{array}{c}0.1+/-0.1 \\
p<0.005\end{array}$ & $\begin{array}{l}1.9+/-0.4 \\
p \ll 0.005\end{array}$ & $\begin{array}{l}0.3+/-0.1 \\
p \ll 0.005\end{array}$ & $\begin{array}{c}34.5+/-15.2 \\
p \ll 0.005\end{array}$ & $\begin{array}{c}68.3+/-16.4 \\
p=0.04\end{array}$ \\
\hline
\end{tabular}


other words, during a dive, deep depredating animals were silent for longer periods of time than under natural conditions. Deep depredating whales also began clicking sooner than naturally-foraging whales after they started a dive [Figs. 5(a) and 7(a)], but the shift was not as dramatic as what was found for shallow depredation.

Also interesting is the fact that deep depredating whales had higher creak rates than under natural situations [Figs. 5(d) and 7(d)], and both KS tests showed highly significant differences between the two [Fig. 7(d)]. The differences arose from two factors. First, most deep depredation dives had creak rates similar to those found under normal conditions, but occasionally very high creak rates were generated during a dive [e.g., Fig. 2(e)], and these relatively infrequent situations cannot be dismissed as statistical outliers. Second, a large number of natural foraging dives contained no creaks $(50 \%)$ vs only $(25 \%)$ for deep-depredation dives, which led to a significant difference between the two distributions.

While the creak rates of deep depredating whales increased significantly, their percentage of creak-pause events did not differ significantly $(p=0.08)$ when compared with natural conditions. This same pattern also appeared with shallow depredation.

\section{Interpreting the meaning of silences after creaks}

Figures 5(d) and 5(e) showed that the creak-pause percentage is much lower in the Gulf of Alaska than measured in more temperate locations, as discussed at the end of Sec. IV A. There were also much larger numbers of dives in the Gulf of Alaska that display no creaks at all.

One interpretation of creak-pause events is that they are indicative of a successful prey capture, as opposed to just a prey capture attempt. Figures 5(d) and 5(e) could thus be interpreted as showing that Alaskan whales generally had lower prey acquisition success rates than whales in the Gulf of Mexico or Ligurian Sea; i.e., the Alaskan whales required more creaks per capture. The fact that Alaskan whales include fish as a natural part of their diet provides one potential explanation for this difference. Figure 5(e) also suggests that shallow depredation required fewer creaks per prey acquisition, although the change was not statistically significant. When Fig. 5(e) is compared to the creak rate distributions in Fig. 5(d), one gets the impression that during both types of depredation a whale may get many more prey opportunities (as shown by higher creak rates), but with only slightly higher capture rates (as shown by the small change in percentage of creak-pause events).

There are several possible alternative interpretations of what a pause following a creak means, including air recycling (Wahlberg et al., 2002) and a simple inability to detect weak creaks on the tag. As discussed in Sec. II D it is unlikely that the low acoustic sampling rate of the tag was missing creak events, because creak events were almost always preceded by an easily-detectable decrease in usual click ICI. The argument that a pause after a creak is primarily due to air recycling seems inconsistent with the observation that creak-pause events in this study were much lower than observed in Miller et al. (2004). Furthermore, if air-recycling were the primary reason why pauses after clicks exist, one would expect that shallow depredation dives would yield relatively fewer pauses after creaks; after all, shallow depredation dives are nearly five times shallower on average that a natural dive, and thus the available air volume inside the animal is five times larger. Instead, one finds that the relative creakpause fraction increases slightly during shallower dives. A third interpretation for a creak-pause event is simply that the received level of a weak creak becomes too low to be detected, and becomes buried in noise. This interpretation is not consistent with what is heard aurally - a creak sound usually transitions to a lower ICI before stopping completely, and this "slowdown" is detectable during most creak-pause situations. Furthermore, no significant difference in creak duration was detected between creak-only $(16 \pm 7 \mathrm{~s})$ and creak-pause $(19 \pm 9 \mathrm{~s})$ events. If creak-pause events were actually weak creaks that become masked, then one would expect the duration of the audible portion of the creak to be shorter during creak-pause situations.

In summary, the interpretation of creak-pause fraction that is most consistent with our analysis is that the fraction is a measure of relative capture success. Our results indicate that depredating whales have many more opportunities to acquire prey, but have to expend as much effort per target as under natural foraging conditions. Both creak rate and creakpause fraction might provide useful proxies for measuring depredation attempts and depredation capture rates, provided that the proper passive acoustic configurations are used, and the ranges of the instruments from the activity are not too great.

\section{Interpretation of deep vs shallow depredation}

While the cumulative distributions of most parameters during deep depredation were shown to be statistically different from those derived from natural behavior, the differences between mean and median values are slight, with substantial overlap in standard deviation. In other words, even though the animals clearly associate themselves with hauling fishing vessels, many aspects of their acoustic and dive behavior remain similar to natural behavior. The most prominent exceptions are much shorter ICIs and higher creak rates displayed during deep depredation. What could the animals be doing around the fishing vessels? Our favored interpretation is that numerous sablefish are being shaken loose from the longline, or "spun off," during the haul to the surface. A recent study by Sigler et al. (2008) used timers triggered to individual longline hooks to discover that up to one-third of the hooks triggered on the ocean floor had no fish when recovered on the surface. Some fish may have struck the bait and not been hooked, or may have escaped when hooked on the bottom, but hooks can also tear from the relatively soft mouths of the cod as they are being hauled to the surface. Underwater video of sperm whales approaching longlines shows one case of a whale approaching the line after a fish had spun loose (Mathias et al., 2009).

These spun-off fish would make easy targets for sperm whales, which naturally consume such prey, and thus could feed in a natural manner. As the fish are free-swimming, the 
foraging success rate [as represented by the creak-pause percentage in Figs. 5(e) and 7(e)] would remain similar to natural levels, but whales have more opportunities to target fish in the mid-water column, thus explaining the generally higher creak rates per dive [Figs. 5(d) and 7(d)]. If most fish happen to spin off relatively close to the ocean floor, then the whales would still have to dive deep to reap the rewards, explaining why the maximum dive depths are relatively unchanged. The low ICI suggests the animals are using their sonar to monitor something at close range. For example, ICI rates have been associated with the two-way travel time of sound to the ocean floor (Thode, 2002) or to a feeding patch midway in the water column (Zimmer, 2003). Making the same assumption, our best guess for the existence of a median ICI of $0.5 \mathrm{~s}$ for deep depredating whales is that they are monitoring a target $300-400 \mathrm{~m}$ away, such as the long line and/or hauling vessel, perhaps to coordinate their dive location at depth. Additional data is therefore needed to determine exactly what sperm whales are doing during this apparent deep-depredation behavior. Upcoming fieldwork includes deploying vertical arrays close to the sablefish survey vessel to estimate the whales depth and range relative to the longline.

While deep depredation seems superficially very similar to natural behavior, shallow depredation differs from natural behavior in almost every parameter measured. Short, shallow dives with high creak rates indicate that the animal is not waiting long for feeding opportunities, so spun-off fish are unlikely to be the sole source of opportunity for this behavior. In 2006 SEASWAP used an underwater video camera to record a whale biting a longline at a shallow depth $(70 \mathrm{~m})$ (Mathias et al., 2009). This video documented that sperm whales can manipulate the line to create tension under a shallow depredation state. Essentially the whale created situation for a fish to spin-off the hook. This video also demonstrated that the animals still actively creak while biting the longline, even under good visual conditions (Mathias et al., 2009). Thus the 5\% decrease in catch rate reported by Sigler et al. (2008) is likely an underestimation as their study only used damaged sablefish as evidence of depredation.

Another interesting aspect of the shallow depredation state is that the animals' behavior does not quite revert to normal once the haul is completed. For example, the whale tagged on 17 July 2007, shown in detail in Fig. 3, shows the most extreme deviations from natural behavior during vessel hauls, but also displays intriguing behavior long after the haul is completed. After depredating the whale returned to dive depths down of about $400 \mathrm{~m}$, similar to natural foraging depths in this region. However, the acoustic record from the tag reveals that the whale had little to no acoustic activity: the whale produced almost no creaks, and occasionally even no usual clicks; periods of complete silence of up to several minutes at depth were common. This behavior lasted for at least six hours (until the tag released) and suggests that the whale did not forage for a long period of time after depredating for several hours. The animal may be transiting to a new location; however, it is unclear why the whale continues to dive to such deep depths. No killer whales (Orcinus orca) or other known predators were observed by the tagging RHIB during daylight hours. In general, Fig. 7(d) indicates that animal tag records associated with shallow depredation also tend to be associated with lower levels of acoustic activity during the "natural foraging" sections in the rest of the record. One possible implication is that animals needed to forage less after a profitable round of shallow depredation.

Why do two distinct types of depredation behavior exist? Three possible explanations include conspecific competition, individual preference, and offal feeding, none of which can be rejected based on the current available data. Up to ten sperm whales have been documented depredating a single line simultaneously, and one might argue that the more whales present, the more "aggressive" the depredation behavior might become as animals compete over the haul, driving them to forage deeper along the longline. The tag records may also simply be revealing that each individual has a unique approach to depredation, arising from different levels of motivation, experience, or preference. Our observations show sperm whales have multiple methods for removing fish off a line, as evidenced by the presence of both empty hooks and biting the fish, leaving shredded parts on the hook. The fact that no individual displays both deep- and shallow-depredation behavior lends some weight to this latter interpretation. Finally, shallow depredation may be more common when the discard from cleaned fish, or "offal" is thrown overboard. For example, the F/V Prowler dresses its fish before storage, thus generating substantial offal discard.

\section{Insight into potential depredation countermeasures}

Sperm whales display at least two different types of behavior when depredating, and this factor must be considered when developing countermeasures, because we do not want to trade off shallow depredation, only to increase the incidence of deep depredation, and vice versa. Therefore a combination of countermeasures might be necessary to target both shallow and deep depredation.

The results of this study have several practical implications when considering ways depredation could be reduced. First, both shallow and deep depredation behaviors are characterized by increased acoustic activity by the animal, a result suggesting passive acoustic monitoring could identify depredation behavior. Measuring creak rates could indicate the number of depredation attempts per unit time occurring in the vicinity of the longline, provided that the acoustic monitoring gear is not too distant from the hauling site. Our detection range estimates for sperm whale creaks, based on empirical measurements, suggest ranges between 3.3 and $10 \mathrm{~km}$, depending on sea state and animal orientation. Measuring the fraction of creaks that are associated with pauses may also provide a measure of depredation success per unit time, although this interpretation remains speculative. These observations are important because current methods of flagging depredation rates (visual evidence of depredation on fishes) underestimate true depredation activity levels. Thus, the identification of accurate acoustic metrics for depredation attempts/success may provide a crucial step in evaluating depredation countermeasures over reasonable time scales. 
The second implication is that if spin-off fish or offal feeding provide a convenient entry for whales to learn depredation, then one of the simplest long-term ways to discourage depredation would be to discover gear modifications that reduce the odds of accidentally spinning off a fish, once it is caught, or dumping offal all at once after a haul, instead of tossing it piecemeal during a call.

The acoustic results presented here can also help predict the distances whales are willing to swim to depredate vessels, which then provides a third implication: that the manner in which a vessel sets gear may be more important than anything the vessel does when hauling gear. We arrive at this conclusion by first assuming that the number of creaks detected per unit time is closely related to the number of prey consumed per unit time. This assumption can be checked by using estimates of average male sperm whale lengths in the North Pacific Ocean, empirical relationships between length and weight (Omura, 1950; Lockyer, 1981), and estimates of energetic needs (Sergeant, 1969; Kleiber, 1975; Clarke, 1980; Lockyer, 1981). We estimate that male sperm whales in this study would require $132 \pm 70$ fish a day for sustenance. Naturally foraging whales produce an estimated average of three to eight creaks per hour in this area, or 50 to 144 creaks per day. The creak rates measured are thus consistent with the estimated energetic intake rates of sperm whales. The uncertainties in the estimates preclude determining whether creak-pause events are related to caloric intake.

If the measured creak rates truly translate into foraging intakes, then the results presented here indicate that shallow depredating whales can attain three to four times greater calorie intakes per unit time than during natural conditions. A three-hour fishing haul would thus provide the equivalent of nine to 12 hours of natural foraging effort by a whale. Figure 3 may provide some support for this idea (see Sec. III C): after being very active for six hours next to a fishing vessel hauling two longlines, the tagged whale has reduced acoustic activity for at least six hours. These tagging results imply that whales should be willing to swim up to six hours, or up to 30 nautical miles, toward a location where gear is being set. However, once a haul begins, it would only make sense energetically for a whale to swim up to two hours in order to depredate for one hour. Thus, fishing vessels have a large incentive to explore techniques for reducing their acoustic signature when setting gear, and for departing an area once gear is set. Reducing the acoustic signature when hauling will not be as effective in reducing the encounter rate. Furthermore, if vessels can deploy some sort of decoy that can delay the response of a whale to a true haul by even an hour, the incentive to depredate would be substantially reduced.

\section{CONCLUSION}

Over two field seasons 11 bioacoustic tags have been deployed on seven distinct whales, permitting observations of the animals' dive profiles and acoustic behavior during natural and depredation foraging conditions.

No single depredation strategy has been observed; instead, two behavioral states that deviate from natural con- ditions can be identified: deep and shallow depredation. Deep depredating whales display behavior relatively similar to natural foraging dives, but they produce higher creak rates and significantly lower inter-click intervals, and begin clicking sooner after starting a dive. Shallow depredation differs from natural foraging behavior in almost every way: irregular dive and surface durations, many dive inflections, and intense acoustic activity (even at the surface). Creak rates three to four times (even seven times) greater than natural foraging rates have been observed during shallow depredation behaviors, along with slightly higher percentages of creak-pause events. Additional experiments are needed to help determine whether differences in depredation behavior arise from conspecific competition and/or individual preference based on experience.

The identification of a useful "measuring stick" for depredation success is a crucial problem in identifying ways of reducing depredation. This study suggests that passive acoustic monitoring could remotely detect prey capture attempts, provided that an appropriate configuration of acoustic hydrophones is deployed sufficiently close to the depredation activity. Preliminary measurements made from several autonomous hydrophones deployed around commercial hauling activities found that creaks could be detected at $3.3 \mathrm{~km}$ range under sea state 2 conditions, with an SNR sufficient to permit possible detection out to $10 \mathrm{~km}$ range in similar conditions.

Potential depredation countermeasures suggested by this study include modifying gear to reduce spin-off fish rates, restricting offal discard, reducing noise generated when setting gear, not loitering around deployed gear, and setting decoy buoys to delay the response of whales to hauling activity by around one hour.

\section{ACKNOWLEDGMENTS}

The authors thank Bill Burgess of Greeneridge Sciences and Joe Olson of Cetacean Research Technologies for providing the tags, flotation, and attachment systems. Erin Oleson of the Scripps Whale Acoustic Lab gave us useful advice on tag deployments on sperm whales. We also thank Jen Cedarleaf, Melania Guerra, and Lauren Wild for their help during data collection. Visual identifications of sperm whales was possible thanks to Jen Cedarleaf and Lauren Wild of the University of Alaska, SE whale research lab. Jay Barlow provided advice on statistical analysis, and Bill Hodgkiss provided advice on the manuscript. The authors thank Tory O'Connell for comments to improve the discussion on depredation strategies. This work was supported by the North Pacific Research Board, a National Geographic Exploration grant, and the Joint Industry Project of the Oil and Gas Producers Association.

Ashford, J. R., Rubilar, P. S., and Martin, A. R. (1996). "Interactions between cetaceans and longline fishery operations around South Georgia," Marine Mammal Sci. 12(3), 452-457.

Berzin, A. (1971). "The sperm whale" [Izdatel'stvo "Pishchevaya Promyshlennost"], translated from Russian by E. Hoz and Z. Blake (Israel Program for Scientific Translations, Jerusalem) (available from the U.S. Department of Commerce, National Technical Information Service, Springfield, VA). 
Bonferroni, C. E. (1936). "Teoria statistica delle classi e calcolo delle probability (Statistical theory of classes and calculating the probability,)" Pubbl. R. Ist. Super. Sci. Econ. Commerc. Firenze 8, 3-62.

Burgess, W. C., Tyack, P. L., Le Boeuf, B. J., and Costa, D. P. (1998). “A programmable acoustic recording tag and first results from free-ranging northern elephant seals," Deep-Sea Res. II 45(7), 1327-1351.

Capdeville, D. (1997). "Interaction of marine mammals with the longline fishery around the Kerguelen Island (Division 58.5.1) during the 1995/96 cruise," Ccamlr Sci. 4, 171-174.

Clarke, M. R. (1980). "Cephalopoda in the diet of sperm whales of the southern hemisphere and their bearing on sperm whale biology," Discov. Rep. 37, 1-324.

DeRuiter, S. L., Bahr, A., Blanchet, M. A., Hansen, S. F., Kristensen, J. H., Madsen, P. T., Tyack, P. L., and Wahlberg, M. (2009). "Acoustic behaviour of echolocating porpoises during prey capture," J. Exp. Biol. 212, 3100-3107.

Douglas, L. A., Dawson, S. M., and Jaquet, N. (2005). "Click rates and silences of sperm whales at Kaikoura,” J. Acoust. Soc. Am. 118, 523-529.

Evans, K., and Hindell, M. A. (2004). "The diet of sperm whales (Physeter macrocephalus) in southern Australian waters," ICES J. Mar. Sci. 61, 1313-1329.

Goldbogen, J. A., Calambokidis, J., Shadwick, R. E., Oleson, E., McDonald, M., and Hildebrand, J. A. (2006). "Kinematics of foraging dives and lungefeeding in fin whales," J. Exp. Biol. 209, 1231-1244.

Goold, J. C., and Jones, S. E. (1995). "Time and frequency domain characteristics of sperm whale clicks,” J. Acoust. Soc. Am. 98, 1279-1291.

Gordon, J.C. D. (1987). "Behavior and ecology of sperm whales off Sri Lanka," Ph.D. dissertation, University of Cambridge, Cambridge, UK.

Jaquet, N., Dawson, S., and Douglas, L. (2001). "Vocal behavior of male sperm whales: Why do they click?," J. Acoust. Soc. Am. 109, 2254-2259.

Johnson, M., Aguilar Soto, N., and Madsen, P. T. (2009). "Studying the behaviour and sensory ecology of marine mammals using acoustic recording tags: a review," Mar. Ecol. Prog. Ser. 395, 55-73.

Johnson, M., Madsen, P. T., Zimmer, W. M. X., de Soto, N. A., and Tyack, P. L. (2004). "Beaked whales echolocate on prey," Proc. R. Soc. London, Ser. B. 271, 383-386.

Kawakami, T. (1980). "A review of sperm whale food," Sci. Rep. Whales Res. Inst. 32, 199-218.

Kleiber, M. (1975). The Fire of Life: An Introduction to Animal Energetics (Krieger, Huntington, NY)

Lockyer, C. (1981). "Estimates of growth and energy budget for the sperm whale, Physeter Catadon," FAO Fish. Ser. (5) Mamm. Sea 3, 489-504.

Madsen, P. T., Wahlberg, M., and Mohl, B. (2002). "Male sperm whale (Physeter macrocephalus) acoustics in a high latitude habitat: implications for echolocation and communication," Behav. Ecol. Sociobiol. 53, 31-41.

Mathias, D., Thode, A., Straley, J., and Folkert, K. (2009). "Relationship between sperm whale (Physeter macrocephalus) click structure and size derived from videocamera images of a depredating whale," J. Acoust. Soc. Am. 125(5), 3444-3453.

Mellinger, D. K., Stafford, K. M., and Fox, C. G. (2004). "Seasonal occurrence of sperm whale (Physeter macrocephalus) sounds in the gulf of Alaska," Marine Mammal Sci. 20(1), 48-62.

Miller, P. J. O., Aoki, K., Rendell, L.E., and Amano, M. (2008). "Stereotypical resting behavior of the sperm whale," Curr. Biol. 18(1), 21-23.

Miller, P. J. O., Johnson, M. P., and Tyack, P. L. (2004). "Sperm whale behaviour indicates the use of echolocation click buzzes 'creaks' in prey," Proc. R. Soc. London, Ser. B 271, 2239-2247.

Nolan, C. P., and Liddle, G. M. (2000). "Interactions between killer whales (Orcinus orca) and sperm whales (Physeter macrocephalus) with a longline fishing vessel," Marine Mammal Sci. 16(3), 658-664.
Okutani, T., and Nemoto, T. (1964). "Squids as the food of sperm whales in the Bering Sea and Alaska Gulf," Sci. Rep. Whales Res. Inst. Tokyo 18, $111-122$.

Omura, H. (1950). "On the body weight of Sperm and Sei whales located in the adjacent water of Japan," Sci. Rep. Whales Res. Inst. Tokyo 4, 1-13.

Papastavrou, V., Smith, S. C., and Whitehead, H. (1989). "Diving behavior of the sperm whale, Physeter macrocephalus, off the Galpagos Islands," Can. J. Zool. 67, 839-846.

Perez, M. A. (2006). "Analysis of marine mammal bycatch data from the trawl, longline, and pot groundfish fisheries of Alaska, 1998-2004, defined by geographic area, gear type, and target groundfish catch species," U.S. Department of Commerce, NOAA Technical Memo No. NMFSAFSC167.

Purves, M. G., Agnew, D. J., Balguerias, E., Moreno, C. A., and Watkins, B. (2004). "Killer whale Orcinus orca and sperm whale Physeter macrocephalus interactions with longline vessels in the Patagonian toothfish fishery at South Georgia, South Atlantic," Ccamlir Sci. 11, 111-126.

Sergeant, D. E. (1969). "Feeding rates of Cetacea," Fisk. Dir. Skr. Serie Havundersok. 15(3), 246-258.

Sigler, M. F., Lunsford, C. R., Straley, J. M., and Liddle, J. B. (2008). "Sperm whale depredation of sablefish longline gear in the northeast Pacific Ocean," Marine Mammal Sci. 24(1), 16-27.

Straley, J., Lidde, J., Thode, A., Folkert, K., O'Connell, V., Behnken, L., and Mathias, D. (2009). "Testing low-cost methods to reduce sperm whale depredation in the Gulf of Alaska: Is avoidance a viable strategy?," presented at the 18th Biennial Conference on the Biology of Marine Mammals, Quebec, Canada.

Surlykke, A., Futtrup, V., and Tougaard, J. (2003). "Prey-capture success revealed by echolocation signals in pipistrelle bats (Pipistrellus pygmaeus), ” J. Exp. Biol. 206, 93-104.

Teloni, V., Johnson, M. P., Miller, P. J. O., and P. T. Madsen (2007). "Shallow food for deep divers: Dynamic foraging behavior of male sperms whales in a high latitude habitat," J. Exp. Mar. Biol. Ecol. 354, 119-131.

Thode, A., Mellinger, D. K., Stienessen, S., Martinez, A., and Mullin, K. (2002). "Depth-dependant features of diving sperm whales (Physeter macrocephalus) in the Gulf of Mexico," J. Acoust. Soc. Am. 116, 245-253.

Thode, A., Straley, J. M., Tiemann, C. O., Teloni, V., Folkert, K., O'Connell, V., and Behnken, L. (2006). "Sperm Whale and Longline Fisheries Interactions in the Gulf of Alaska," in North Pacific Research Board Final Report No. F412.

Wahlberg, W. (2002). "The acoustic behaviour of diving sperm whales observed with a hydrophone array,” J. Exp. Mar. Biol. Ecol. 281, 53-62.

Watwood, S. L., Miller, P. J. O., Johnson, M. P., Madsen, P. T., and Tyack, P. L. (2006). "Deep-diving foraging behaviour of sperm whales (Physeter macrocephalus)," J. Anim Ecol. 75(3), 814-825.

Whitehead, H. (2003). Sperm Whales: Social Evolution in the Ocean (University of Chicago Press, Chicago).

Whitehead, H., Brennan, S., and Grover, D. (1992). "Distribution and behaviour of male sperm whales on the Scotian Shelf," Can. J. Zool. 70, 912-918.

Whitehead, H., and Weilgart, L. (1990). "Click rates from sperm whales," J. Acoust. Soc. Am. 87, 1798-1806.

Whitehead, H., and Weilgart, L. (1991). "Patterns of visually observable behaviour and vocalizations in groups of female sperm whales," Behaviour 118, 275-296.

Worthington, L. V., and Schevill, W. E. (1957). "Underwater sounds heard from sperm whales," Nature 180(4580), 291.

Zimmer, W. M. X., Johnson, M.P., D’Amico, A., and Tyack. P. L. (2003). "Combining data from a multisensor tag and passive sonar to determine the diving behavior of a sperm whale (Physeter macrocephalus)," IEEE J. Oceanic Eng. 28(1), 13-28. 